\title{
Papel dos Contratos na Coordenação Agro-Industrial: um olhar além dos mercados $^{1}$
}

Decio Zylbersztajn²

Resumo: O presente ensaio parte da pergunta da razão explicativa para o limitado uso do enfoque contratual para o estudo das firmas na Economia Agrícola no Brasil. Discute a relevância dos contratos para o avanço da teoria da firma, apresenta uma evolução dos enfoques aplicados ao estudo da coordenação de sistemas agroindustriais no Brasil e em centros internacionais e finaliza apresentando uma agenda de pesquisa e ensino para a Economia Aplicada em geral e Economia Agrícola em particular.

Palavras Chave: custos de transação, contratos na agricultura, teoria da firma.

Classificação JEL: Q12, L22

\footnotetext{
${ }^{1}$ Aula magna do professor Decio Zylbersztajn apresentada no XLIII Congresso da Sociedade Brasileira de Economia e Sociologia Rural - SOBER, Ribeirão Preto, 2005.

${ }^{2} \mathrm{O}$ autor é Professor Titular da Faculdade de Economia, Administração e Contabilidade da Universidade de São Paulo. Fundou e dirigiu o PENSA- Programa de Estudos de Agronegócios - de 1991 a 2005. É Fellow da International Agribusiness Management Association, é membro do Board da International Society for the New Institutional Economics. Fundou e coordena o Centro de Estudos de Direito, Economia e Organizações na USP-CEDEO e é pesquisador CNPq. Agradece aos alunos de iniciação científica e de pós-graduação, participantes do programa de pesquisas em Sistemas Agroindustriais do PENSA. Especial agradecimento à coordenadora das "oficinas pensa”, Professora Sylvia M. Saes, pela organização das discussões teóricas do PENSA e ao Dr. Eliseu Alves pelo estímulo intelectual que sempre representou no meu trabalho. dezylber@usp.br
} 
Abstract: This essay departs from the question about the limited adoption of the contractual approach in the field of Agricultural Economics in Brazil. It discusses the relevance of the contractual approach to the theory of the firm, presents the evolution of the studies of coordination in food chains in Brazil and abroad, and concludes suggesting a research and educational agenda for applied Agricultural Economics.

Key Words: transaction cost, agriculture contracts, firm theory

JEL Classification: Q12, L22

If an economist finds something - a business practice of some sort or another - that he does not understand, he looks for a monopoly explanation.

Ronald Coase Prêmio Nobel em Economia

\section{Introdução}

A Economia aplicada à agricultura tem seu desenvolvimento relacionado à teoria da firma, em que pese a relevância dos temas macroeconômicos. Os estudos das relações de produção, sempre tiveram destaque na pesquisa e ensino no campo aplicado da Economia Agrícola. O estudo da firma agrícola tal como enfocada por Heady e Dillon (1961), exerceu influência na academia, a partir da ótica da função de produção, motivou relevante volume de pesquisa empírica focalizada no papel dos preços na alocação eficiente dos recursos.

Embora os estudos da firma como função de produção tenham caído em desuso, as aplicações empíricas da teoria da produção ao estudo da economia agrícola foram, e ainda são, direcionadas ao estudo do funcionamento dos mercados e suas derivações. Políticas de preço, impactos de distorções do funcionamento livre do mercado são a tônica da tradicional teoria, seja sob a ótica da firma, ou sob a ótica da demanda, que permite, a partir dos pressupostos dos mercados perfeitos, estudar os impactos de políticas públicas e intervenções de diferentes naturezas. Os anos de pós-guerra foram caracterizados pela revisão do papel do Estado 
levando ao uso da teoria da firma para estudar impactos de políticas públicas na oferta. Assim os estudos de crédito, de mudanças tecnológicas, de barreiras ao comércio internacional incluindo distorções cambiais, efeitos de impostos e subsídios tiveram o seu momento de relevância. Os estudos de desenvolvimento econômico da mesma forma tiveram o seu momento (e talvez vivam um renascimento nos anos 2000) com relevantes debates conceituais e teóricos entre estruturalistas marxistas e neoclássicos. Seriam os preços ou as mudanças estruturais que trariam impactos e indicariam os caminhos do desenvolvimento?

O foco da análise ficava entre o intervencionismo, nas suas diversas formas, ou o livre papel dos mercados. Os debates foram profícuos e, no âmbito da Economia Agrícola permitiram relevantes contribuições, como de Rui Miller Paiva no Brasil e Hans Binswanger (1974) nos Estados Unidos, no estudo do papel indutor dos preços na mudança tecnológica, e de Pastore (1969) no estudo resposta da oferta aos estímulos de preços, em contraste com a proposta de alteração estrutural agrário-reformista.

Foi um bom momento da Economia Agrícola no Brasil, pois o debate das idéias era a tônica central. Em meio a este profícuo ambiente acadêmico, não se notava um tema ausente no debate que se travava e nas pesquisas sobre a firma, que marcaram a Economia Agrícola. A firma do mundo real não se assemelhava em nada à firma da teoria neoclássica. Se quiséssemos discutir estratégias, estruturas internas das organizações ou mesmo relações inter-organizacionais as ferramentas da teoria da firma mostravam-se impróprias. Como afirma Harold Demsetz (1995), a teoria da firma foi desenhada e se presta ao estudo da sua existência e do funcionamento dos mercados e não do funcionamento intrínseco das organizações do mundo real. O papel dos preços é oferecer informações e não de coordenar a produção. Neste sentido a teoria neoclássica da firma é adequada ao seu propósito, que não é o de estudar as organizações.

Adicionalmente, a teoria da firma focaliza apenas a produção com o propósito de maximização de lucros, deixando à margem o estudo de outras formas de organização, como as organizações sem fins lucrativos, as firmas políticas e as associações e entidades de representação ${ }^{4}$. Talvez o distancia-

\footnotetext{
${ }^{4}$ Gary Becker deu relevante contribuição ao estudo da organização da produção doméstica, e outras formas de produção menos tradicionais, como as organizações ligadas ao crime.
} 
mento entre a teoria da firma e a firma observada no mundo real tenha sido a causa de tanto desestímulo aos alunos, especialmente de graduação, que se desencantam com as disciplinas introdutórias de micro-economia ${ }^{5}$.

Decorre uma pergunta. Se a teoria neoclássica da firma não foi desenhada para estudar a firma do mundo real e nem o seu funcionamento interno, quais as teorias que se prestam para tal análise? Quais as teorias que nos permitem estudar, formular e testar hipóteses a respeito das decisões sobre formas alternativas de organizar a produção? Como discernir entre a escolha eficiente de uma cooperativa ou uma empresa de propriedade individual. Como avaliar se a produção deve ser organizada na forma de uma rede de firmas independentes, ou se a firma deve fazer todas, ou algumas, das etapas de produção? Em suma, como, além de justificar a existência da firma, poderia a teoria, que leva o seu nome, evoluir para a compreensão do seu funcionamento intrínseco? ${ }^{6}$

Enquanto o debate no Brasil se situava entre os extremos do liberalismo Neoclássico e do intervencionismo Estruturalista-Marxista, avançava no cenário internacional da teoria econômica uma silenciosa mudança de paradigma. Esta ocorria no campo da teoria e da prática da pesquisa em Teoria Econômica Aplicada, da qual ficamos ausentes por alguns anos. Como afirma Péguy, citado por Williamson (1996, p.13), "quanto mais crescemos enquanto cidadãos, menos acreditamos em revelações súbitas, em súbitas paixões que não sejam acompanhadas de trabalho árduo, sério, molecular e definitivo". Tal comentário é especialmente verdadeiro para a pesquisa acadêmica.

O novo marco teórico houvera sido plantado por Ronald Coase no seu artigo "The Nature of the Firm (1937)", depois complementada pelo artigo "The Problem of Social Cost (1960)". Basicamente Coase estava preocupado com as organizações do mundo real, como deixou claro no

\footnotetext{
${ }^{5}$ Em especial nas carreiras que demandam formação básica em teoria econômica e que não tem espaço na grade disciplinar para cobrir vários os fundamentos de teoria microeconômica para chegar, de modo consistente, ao estudo de mercados imperfeitos e de organização industrial. É o caso dos cursos de direito, de administração e de ciências contábeis.

${ }^{6}$ A contribuição de Knight é relevante e se baseia no risco e sua relação com o lucro, entretanto inconsistente para acomodar as críticas sobre o funcionamento da firma. Ver F.H.Knight.1965. Risk, Uncertainty and Profit. New York, Harper and Row.
} 
seu discurso ao receber o prêmio Nobel de Economia em 1991. Ao fazê-lo discutiu as razões explicativas para a existência da firma com base nos custos comparativos da organização interna e de produção via mercado, e lançou as bases para o estudo das formas alternativas de organização das firmas contratuais. Reconheceu que os mercados não funcionavam a custo zero, tampouco a organização interna da firma era desprovida de custos. A sua preocupação foi, continuamente, de chamar a atenção dos economistas para os fenômenos do mundo real e para o rico laboratório vivo do mundo das organizações, que estavam à espera de estudo cuidadoso ${ }^{7}$. Quais as razões explicativas para tanta variabilidade nas formas das organizações?

Suas indagações, e a teoria que dela evoluiu, abriram caminho para a análise da organização interna das firmas e das relações entre elas, seja no suprimento de matérias primas ou na distribuição dos seus produtos. O ponto de partida é simples: existem custos associados ao funcionamento dos mercados que podem exceder os custos da organização interna. Assim, a firma apresentada por Coase tem natureza contratual, e aparece como uma resposta eficiente dos agentes econômicos para coordenar a produção.

Coase apontou a existência de custos para realizar as transações, o que não elimina a possibilidade da sua condução via mercado; portanto, o sistema de preços continua sendo relevante, podendo funcionar como mecanismo alocador eficiente de recursos em casos particulares. Entretanto, Coase nos revela que, basta um olhar ao nosso redor para percebermos que o mecanismo de mercado é exceção e o mecanismo contratual a regra, como mecanismo para alocação dos recursos na sociedade.

Em seu discurso ao receber o Prêmio Nobel, Coase criticou a visão da firma como função de produção, sugerindo ser um estereótipo que não tem aderência ao mundo real e nem tem vigor analítico que sugira a sua adoção. O seu artigo de 1937, escrito no início da sua carreira, só teve o impacto pleno a partir da década de 1970. Foram trinta anos em espera lacônica.

\footnotetext{
${ }^{7}$ No congresso inaugural da International Society for the New Institutional Economics, Coase afirmou que os biólogos foram mais competentes do que os economistas para estudar os sistemas complexos. Discurso gravado. Washington University, Saint LouisMo.setembro de 1997.
} 
A partir da visão da firma como um "nexo de contratos" abriu-se a possibilidade do estudo das organizações como "arranjos institucionais" que regem as transações, seja por meio de contratos formais ou de acordos informais, os primeiros amparados pela lei, o segundo amparado por salvaguardas reputacionais e outros mecanismos sociais. As instituições foram re-introduzidas na teoria microeconômica, ${ }^{8}$ e passou-se a considerar a firma como um nexo de contratos cuja estrutura - forma de governança - varia de modo previsível de acordo com variáveis passíveis de análise, pautadas pelas regras institucionais. Emergiu uma família de teorias que permitiam a elaboração de hipóteses e aplicações aos problemas empíricos do mundo real. O leiloeiro Walrasiano entrara em agonia.

Teorias da firma de base contratual avançaram a partir de múltiplas raízes. A Economia dos Custos de Transação (Williamson,1985,1996), Teoria dos Custos de Mensuração (Barzel, 2002), ambas ancoradas em Coase, Teoria dos Contratos Incompletos (Hart,1995), Teoria com Base nos Recursos (Langlois,1998), a Teoria das Redes (Thorelli,1986), a teoria de Agência (Pratt e Zeckhauser,1985), entre outras. A re-construção de pontes entre a Teoria Econômica e a Sociologia, e mais recentemente com as ciências cognitivas com o questionamento a respeito do pressuposto de racionalidade, resultaram da quebra de paradigma. O ponto central é de que instituições são relevantes, são passíveis de análise, afetam e são afetadas pelas firmas e organizações. No âmbito da Nova Economia Institucional voltam à cena os temas explicativos da gênese e evolução das instituições, lideradas por Douglass North, e da origem e evolução das organizações, entre as quais se destacam as firmas.

Cabe indagar qual foi a reação da Economia Agrícola, no mundo e no Brasil, em resposta ao movimento que se consolidava nos anos 70-80, e como a pesquisa empírica respondeu às novas demandas. Sendo os contratos tão relevantes, quais as razões para os Economistas Agrícolas, em especial no Brasil, relutarem em utilizar os seus ferramentais teóricos para o seu estudo? Se o estudo a economia dos contratos permite analisar a organização interna das firmas, isto implica em uma verdadeira avenida de oportunidades para quem se interessa pela economia aplicada. Quais as razões da relutância em avançar?

\footnotetext{
${ }^{8}$ Certamente, e com razão, os Marxistas dirão que nunca deixaram-nas de lado.
} 
O presente ensaio pretende concluir algo a respeito desta indagação. O texto está estruturado em quatro partes. Na segunda parte evidências da relevância dos contratos na coordenação dos agronegócios serão apresentadas. Na terceira parte algumas das teorias relevantes das organizações serão apontadas e uma avaliação do progresso da teoria da firma nos sistemas agroindustriais será indicada. A quarta parte apresenta conclusões, seguida por comentários sobre as principais linhas de pesquisa em andamento nos principais centros no Brasil e exterior bem como sugestões para pesquisa empírica aplicada à agricultura e ensino da teoria da firma.

\section{Mercados e Contratos: olhando o mundo que nos cerca.}

O exemplo mais utilizado do funcionamento dos mercados competitivos nos cursos de micro-economia é o dos mercados agrícolas. O que se costuma ressaltar são as características dos mercados competitivos como: os produtos são homogêneos, existe um grande número de compradores e de ofertantes, a informação é perfeita e, portanto, o sistema de preços deve dar conta de alocar os recursos de modo adequado. Os produtos commodities são os exemplos mais próximos que se pode dar de um mercado competitivo; portanto, a teoria sugere que não se deve encontrar outros mecanismos de coordenação que não o sistema de preços. Entretanto a realidade observada nos convida a questionar tal princípio. Na agricultura abundam os exemplos de contratos envolvendo agricultores e ofertantes de insumos, canais de distribuição, bem como de coordenação horizontal.

Contratos e Coordenação: Ao considerar-se a complexa gama de atividades gerenciadas pelos agricultores nos sistemas agroindustriais (SAG's) ${ }^{9}$, percebe-se que relações contratuais formais e acordos de cooperação informais de longo prazo se estabelecem entre os agricultores, os fornecedores de insumos, os traders, as firmas processadoras, e ainda com os supermercados e sistema de distribuição de produtos frescos. Talvez por serem tão óbvios, não se dá a devida importância aos contratos

\footnotetext{
${ }^{9}$ Prefiro utilizar a denominação de Sistemas Agroindustriais a Cadeias Produtivas, por razão que será elucidada no capítulo seguinte.
} 
de acesso à terra, contratos de crédito e de trabalho que são comuns na agricultura brasileira. Menos comuns no Brasil ${ }^{10}$, mas muito relevantes em outros países, são os contratos de aluguel de equipamentos. Segundo dados da FAO, no caso da terra, $62 \%$ dos agricultores nos EUA, 26\% na Espanha, $33 \%$ na Itália, $63 \%$ na Alemanha, 35\% no Reino Unido e $28 \%$ em Portugal, utilizam alguma forma de contrato para acesso à terra. Estudos relevantes que tratam dos contratos tradicionais na agricultura são, os de Cheung (1969), e Allen e Lueck (2002). A implicação imediata da contratação por parte dos agricultores, é a diminuição dos ativos e o aumento da remuneração do capital.

Tais práticas nos informam que existem custos na operação dos mercados e que as partes, contratantes e contratados, preferem muitas vezes, realizar as atividades de suprimento, de produção e distribuição de forma coordenada pela via contratual. Isto implica em afirmar que existe aumento do valor da organização pela via contratual, evitandose custos associados ao funcionamento dos mercados e tal aumento de valor serve de incentivo para as partes envolvidas no contrato.

O outro lado da moeda deve ser ressaltado. A contratação também apresenta custos e exige salvaguardas com respeito a possíveis quebras contratuais. Tais mecanismos podem ter natureza privada e são parte dos arranjos entre os agentes produtivos. Também podem amparar-se em mecanismos públicos dos tribunais, que sinalizam para o cumprimento dos contratos. No caso brasileiro dois problemas são discutidos. O primeiro é o da eficiência do judiciário, que pode não sinalizar os agentes como esperado. O segundo é a fragilização do instituto do contrato, que adquire nova roupagem com o surgimento do conceito jurídico de "papel social do contrato".

Contratos e Coordenação Horizontal: Agricultores também se organizam horizontalmente na forma de relações contratuais ou acordos informais de produção. As vantagens da cooperação estão fartamente tratadas na literatura de ações coletivas, com destaque para a contribuição de Olson (1965). Seja como forma de ganhar em economias de escala, economias de rede, de adicionar valor de forma seletiva, ou para ampliar

\footnotetext{
${ }^{10}$ Cresce o mercado de aluguel de equipamentos no Brasil, o que mereceria um olhar mais detalhado por parte dos economistas agrícolas.
} 
o potencial de coordenação com a indústria processadora, existem incentivos para a organização horizontal ampliadora de valor da organização. A literatura aplicada de cooperação horizontal no campo da Economia Agrícola veio a florescer com os estudos das organizações cooperativas, com destaque para os estudos de Michael Cook nos Estados Unidos e Sigismundo Bialoskorski e Fábio R. Chaddad no Brasil.

Contratos e Coordenação Vertical: A literatura de coordenação vertical é muito rica e mostra evidências de que os contratos representam significativa parcela da produção da agricultura e pecuária em todo o mundo. MacDonald et al (2004) mencionam que 36 \% do valor da produção da agricultura norte americana se dá sob forma contratual (tabela 1).

Tabela 1. Incidência de Contratos na Agricultura dos EUA

\begin{tabular}{cc}
\hline Ano & $\%$ contratos \\
\hline 1969 & 12 \\
1991 & 28 \\
2004 & 36 \\
\hline
\end{tabular}

Fonte: MacDonald, et. al,2004

O estudo conduzido pelo USDA indica que a adoção de contratos é mais freqüente nos produtores de maior escala e explora as razões pelas quais os produtores preferem contratos ao invés de comercializar via mercados, destacando a redução de riscos e a economia de custos de transação como as mais relevantes. Os contratos não se dão apenas na atividade de comercialização. O USDA estima que em 2001, 24.6\% dos produtores alugaram equipamentos, $17.5 \%$ contratavam trabalho, $60.7 \%$ custom work, $19.3 \%$ faziam contratos de transporte, $69.6 \%$ faziam contratos de crédito e $41.7 \%$ realizavam algum tipo de contrato de produção e marketing.

A Tabela 2 indica o percentual de contratos observados em produtos escolhidos na agricultura norte americana no período entre 1991 e 2001 . 
Tabela 2. Evolução percentual da produção sob contratos em commodities, por ano, na agricultura Norte Americana.

\begin{tabular}{lccccc}
\hline Produto & $1991-93$ & $1994-95$ & $1996-97$ & $1998-00$ & 2001 \\
\hline Açúcar & 91.1 & 83.7 & 75.1 & 89.0 & 95.5 \\
Arroz & 19.7 & 25.2 & 25.8 & 30.5 & 38.5 \\
Algodão & 30.4 & 44.5 & 33.8 & 42.9 & 51.7 \\
Frutas & na & 64.2 & 56.8 & 65.4 & 59.0 \\
Gado & na & 19.0 & 17.0 & 24.3 & 20.9 \\
Suínos & na & 31.1 & 34.2 & 55.1 & 60.6 \\
Aves & 88.7 & 84.6 & 84.0 & 88.8 & 88.1 \\
\hline
\end{tabular}

Fonte: MacDonald, et. al,2004

Estudo de Martinez e Zering (2004) do USDA indica que os contratos na produção de suínos cresceram significativamente nos anos 90, chegando a $69 \%$ em 2004 , tendo partido de $2 \%$ do total da produção em 1980. Os autores informam que a diminuição das transações realizadas nos mercados spot leva à perda de representatividade dos preços de mercado levantados pelo USDA, bem como não revelam importantes dimensões das transações que são presentes nos contratos, tais como prêmios e outros incentivos. As bases teóricas utilizadas no estudo foram a Economia os Custos de Transação, de Oliver Williamson e a Teoria dos Custos de Mensuração, de Yoram Barzel.

$\mathrm{O}$ estudo do USDA analisa apenas os contratos formais. A teoria ${ }^{11}$ nos convida a pensar nas transações de um modo geral, que podem ter algumas dimensões contratadas e outras dimensões acordadas informalmente. Portanto, os dados indicam apenas parte visível das relações, que certamente são muito mais amplas.

No Brasil as evidências da adoção de contratos nas relações agro-industriais são marcantes. Ainda que, até o presente, o Censo Agropecuário e outras fontes de estatísticas relevantes não incluam esta informação nos seus questionários, os estudos específicos mostram a pluralidade de mecanismos à espera das lentes acadêmicas ${ }^{12}$. Se tomarmos as principais

\footnotetext{
${ }^{11}$ No capítulo seguinte introduzirei a teoria dos custos de mensuração de Yoram Barzel. ${ }^{12} \mathrm{O}$ censo da agricultura norte-americano ou pesquisas aprofundadas coletam informações sobre contratos desde 1969.
} 
culturas relevantes para a agricultura brasileira, poderemos exemplificar o papel que os contratos exercem sobre os tomadores de decisão.

$\mathrm{Na}$ soja, maior exemplo de commodity que se pode vislumbrar, o sistema de preços serve de referência, mas os contratos prevalecem. Estudo de Paes Leme (2004) trabalhou uma amostra de 200 sojicultores em Goiás e Mato Grosso, identificou que 31,5\% dos entrevistados adotaram formas contratuais híbridas envolvendo a venda antecipada a processadoras, indústrias de insumos e produtores de soja. Contratos para entrega futura têm sido observados e estudados por Zylbersztajn (2005), que identifica os problemas de quebras contratuais observados nas safras de 2004-2005 e 2003-2004.

A avicultura segue a mesma tendência da encontrada nos EUA. Estudo de Nogueira e Zylbersztajn (2002) mostra a adoção de contratos na indústria avícola brasileira, evidenciando ser distinta a dinâmica de adoção entre estados no país. Estatísticas da Associação Brasileira dos Exportadores de Frangos indicam que 59,5\% da produção direcionada ao mercado internacional provém de empresas integradas associadas. $\mathrm{O}$ número é sub-estimativa, pois sabe-se que no sul do país os contratos entre produtores e integradores chega próximo a 100\%, sendo menor no Estado de São Paulo onde o mercado spot é mais relevante. Marques (1991) estima que $71 \%$ da produção de São Paulo era coordenada por meio de contratos. O caso dos suínos segue a mesma tendência, com estimativas dos contratos representando 30-40 \% do total da produção.

A indústria de tomates foi estudada por Zylbersztajn e Nadalini (2004) indicando ser a contratação uma prática antiga na indústria, cuja estrutura muda ao longo do tempo. O estudo identifica que a indústria, mais recentemente, prefere reduzir o número de fornecedores contratados, optando por produtores de maior porte, tal como indicado na literatura internacional.

A indústria de sementes é fortemente baseada em contratos de licenciamento entre as organizações detentoras de tecnologia e os multiplicadores. Estudo de Zylbersztajn e Lazzarini (2005) estuda a duração dos contratos entre a EMBRAPA e multiplicadores de sementes de milho. Na mesma vertente os estudos de contratos de franquia em distribuição de alimentos foram analisados por Santos Silva (2004), descrevendo as formas híbridas características dos contratos de franquia em alimentos no Brasil. 
Contratos de acesso à terra são muito comuns no Brasil sendo prática informal típica nas regiões de produção. Tal mercado se organizou regionalmente com a estruturação de bolsas de arrendamento de terras na região do Pontal do Paranapanema em SP e no Triângulo Mineiro em MG. Contratos nos canais de distribuição foram estudados por Neves (2001) bem como contratos de arrendamento industrial (toll processing) com aplicações na indústria de laranja, em Neves (1995).

O Quadro 3 apresenta alguns dos estudos sobre contratos em relações agricultura-indústria no Brasil, sendo indicativo da fertilidade desta área de estudos no Brasil.

Tabela 3. Mercados e Contratos: Evidências na Agricultura

\begin{tabular}{llccc}
\hline Autor & Produto & \multicolumn{2}{c}{ Governança Observada } \\
\cline { 3 - 5 } & & Mercado & Contratos & Hierarquia \\
\hline Leme (2004) & soja & $\mathrm{X}$ & $\mathrm{X}$ & \\
Zylbersztajn e Miele (2005) & vinho & & $\mathrm{X}$ & $\mathrm{X}$ \\
Zylbersztajn e Nadalini (2003) & tomate & & $\mathrm{X}$ & \\
Zylbersztajn et al (2005) & Soja & $\mathrm{X}$ & $\mathrm{X}$ & \\
& Terra & & $\mathrm{X}$ & $\mathrm{X}$ \\
& Crédito & & & $\mathrm{X}$ \\
Zylbersztajn e P. Machado (2003) & Carne & $\mathrm{X}$ & $\mathrm{X}$ & $\mathrm{X}$ \\
Zylbersztajn e Nogueira (2002) & Frango & $\mathrm{X}$ & $\mathrm{X}$ & \\
Mizumoto e Zylbersztajn (2005) & ovo & $\mathrm{X}$ & $\mathrm{X}$ & \\
\hline
\end{tabular}

Além dos exemplos apontados, os contratos são amplamente utilizados na atividade de produção de café, frutas, vinho, e de modo particularmente relevante, os contratos desenhados entre supermercados e supridores, tal como destaca Reardon e Timmer (2005). Os autores indicam a mudança de ênfase da comercialização dos produtos agrícolas que nos anos 50 se baseavam nos mercados spot e as políticas focalizavam a obtenção dos preços corretos. Já os anos 90 indicam a necessidade de coordenar atributos de difícil observação, dificilmente capturados pelo sistema de preços. O autor ressalta o impacto da Nova Economia Institucional e a ênfase em corrigir as instituições. 
Se existe a prática dos contratos, cabe lançar um olhar sobre as razões teóricas explicativas da adoção da prática, o que será feito a seguir.

\section{Evolução da Teoria}

Em adição à lógica Walrasiana, a Nova Economia Institucional propõe duas vertentes analíticas complementares aplicáveis ao estudo das organizações. A primeira pode ser vista como de natureza macro-desenvolvimentista trabalhada por Douglass North, que focaliza a origem, estruturação e mudanças das instituições. A questão central é explicar a origem e mudanças das instituições, vistas como as regras que pautam o comportamento da sociedade. A segunda é de natureza micro-institucional, representada pela economia das organizações, que estuda a natureza explicativa dos diferentes arranjos institucionais observados. Esta vertente tem contribuições de diversos autores como Oliver Williamson (University of California-Berkeley), Harold Demsetz (UCLA), Yoram Barzel (Washington University), e Claude Menard (Paris I-Sorbonne), entre outros. A operação das firmas vistas como arranjos institucionais é pautada pelas regras do jogo (instituições), o que confere a ligação entre as duas vertentes. Ambas vertentes consideram as instituições relevantes a passíveis de análise e a vertente micro-institucional parte da visão da firma como um nexo de contratos..$^{13} \mathrm{O}$ mercado é visto como uma instituição, que demanda regras definidas para sua operação ${ }^{14}$.

Caso os direitos de propriedade não sejam definidos ou garantidos, e no caso de haver choques externos desestabilizadores, e se o comportamento dos agentes econômicos não for benigno e cooperativo, emergem custos para a operação dos mercados, justificando o surgimento dos contratos.

\footnotetext{
${ }^{13} \mathrm{O}$ estudo dos direitos de propriedade representa um dos fundamentos da NEI. As transações não são meras trocas de bens ou serviços, mas são vistas como trocas de direitos de propriedade de dimensões particulares das transações. As regras institucionais afetam as organizações uma vez que afetam os direitos de propriedade, gerando a ligação entre regras institucionais e custos de transação.

${ }^{14}$ Um bom exemplo é o surgimento do Chicago Climate Exchange, que negocia certificados de carbono. Tal mercado só começou a operar após a definição de uma série de regras e métricas que permitiram a redução dos custos para a realização das trocas. Não surpreende que um dos que mais contribuíram para o seu surgimento foi Richard Sandor, ex aluno de Ronald Coase em Chicago.
} 
O chamado "mapa cognitivo das transações" que está representado na Figura 1, foi proposto por Williamson (1985), permite caracterizar as diversas vertentes analíticas úteis para a teoria da firma revisitada. $\mathrm{Na}$ forma de uma chave classificatória, a primeira dicotomia se dá entre as vertentes do monopólio e da eficiência. Aí reside a crítica de Coase para a explicação tradicional da ocorrência das formas contratuais complexas com base no poder de monopólio, encontradas nas interpretações tradicionais da análise da concorrência ${ }^{15}$. A compreensão desta dicotomia é fundamental para pautar ações intervencionistas que interpretam contratos complexos como oriundos do exercício do poder de monopólio, e que podem ser interpretados pelo outro ramo, que é o da eficiência.

Na vertente da eficiência existem duas ramificações importantes. Uma considera possibilidade de elaboração de contratos completos, portanto associadas ao pressuposto neoclássico de racionalidade plena, onde se coloca a teoria da agência. A segunda que tem base no pressuposto da racionalidade limitada e seu corolário que são os contratos incompletos ${ }^{16}$, dando origem às teorias de Economia os Custos de Transação e de Custos de Mensuração, ambas relevantes para o estudo dos contratos em geral e os que envolvem a agricultura, de modo particular.

Assim, os contratos surgem como estruturas de amparo às transações que visam controlar a variabilidade e mitigar riscos, aumentando o valor da transação ou de um conjunto complexo de transações. Um passo conceitual básico foi proposto por Klein, Crowford e Alchian (1978) dando origem à Economia os Custos de Transação. O conceito de quebra contratual oportunista é explorado pelos autores com base em incentivos de apropriação das quase-rendas oriundas de investimentos em ativos específicos. Caso uma parte do contrato realize investimentos específicos, geradores de rendas, na ausência de salvaguardas, parte do seu valor pode ser expropriada ex-post pela outra parte. A especificida-

\footnotetext{
${ }^{15}$ Existe uma clássica fricção entre o campo do "Law \& Economics” com raiz neo-clássica materializado pelo trabalho de Richard Posner e da "Law \& Economics" na vertente da Nova Economia Institucional, materializada pela contribuição de Oliver Williamson. O debate entre os autores foi publicado em série de artigos no Journal of Law and Economics.

${ }^{16} \mathrm{~A}$ impossibilidade de antever todas as contingências futuras leva à impossibilidade de trazer ao momento da contratação, todas as possibilidades futuras que afetarão as partes em um contrato. Um excelente exemplo para sala de aula é o contrato do casamento.
} 
de dos ativos tem um papel central na teoria, e informa qual a perda possível por uma ou todas as partes participantes em um contrato, no caso de ruptura pós-contratual. Quem fez investimentos cuja realocação implique em perdas significativas do valor dos investimentos em ativos específicos, deverá adotar mecanismos que visem reduzir os riscos de perda. A Figura 2 explora o conceito, indicando a necessidade da criação de salvaguardas na presença de ativos específicos.

Figura 1. Mapa Cognitivo dos Contratos

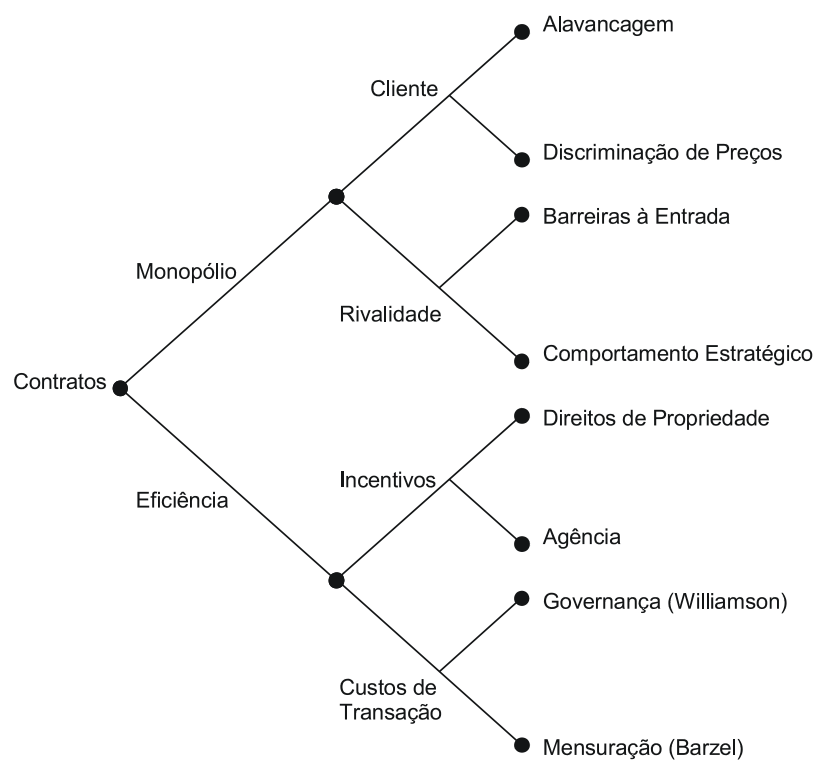

Fonte: Williamson (1985)

Na ausência de ativos específicos não existe necessidade de salvaguardas, representando a situação hipotética onde o mecanismo de preços é suficiente. Na presença de ativos específicos, o nó B representa situação de instabilidade, uma vez que nenhuma salvaguarda foi adotada, implicando em riscos de apropriação de quase-rendas ${ }^{17}$. $\mathrm{O}$ nó $\mathrm{C}$ será eficiente em comparação ao nó B, pois introduz algum tipo de salvaguarda contratual.

${ }^{17}$ Aplica-se aqui o pressuposto de racionalidade limitada, que impede a elaboração de contratos completos, em adição ao pressuposto de oportunismo pós-contratual. São dois pressupostos distintos da teoria neo-clássica. 
Figura 2. Esquema Contratual Simplificado

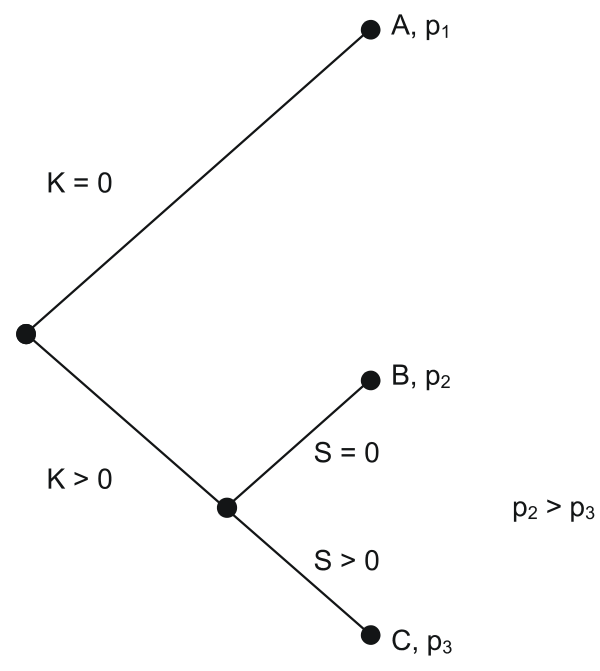

Fonte: Williamson (1996)

Na essência, a ECT considera incentivos de eficiência com base no desenho de arranjos institucionais, que tanto podem ser contratos formais ou outras formas de coordenação amparadas por reputação ou laços sociais. Assume-se a possibilidade da presença de oportunismo pós-contratual, que associada a investimentos em ativos específicos leva os agentes a antecipar e mitigar os problemas pós-contratuais, desenhando medidas de precaução. Os contratos e formas contratuais complexas são explicados pelo racional acima, sendo uma forma de governança intermediária entre o mercado (agentes dispersos e sem investimentos em ativos específicos) e a firma hierárquica, onde as transações são internalizadas.

Um exemplo de apropriação de quase rendas pode ser dado na agropecuária. Considere um pecuarista que recebe a oferta de um frigorífico para adotar uma tecnologia para a produção de um animal precoce e com determinadas características. Para fazer parte do negócio, um investimento em ativos com grau de especificidade maior do que zero deve ser feito pelo pecuarista, para habilitá-lo a ofertar o produto para o frigorífico. Um preço P é definido antes do investimento. Na ausência de salvaguardas (nó A), o pecuarista 
poderá ficar exposto ao risco de receber - a posteriori - um preço menor do que o acordado, que cubra os seus custos fixos, mas que não lhe confere o retorno desejado. A diferença é apropriada pelo frigorífico, caso a alternativa do pecuarista seja o mercado para o produto commodity. O nó B é instável o que demanda a necessidade de um contrato com salvaguardas (migração para o nó C), ou a integração vertical, sendo P2 > P3.

Já a vertente da Economia dos Custos de Mensuração, desenvolvida por Yoram Barzel, parte do conceito de eficiência, mas tem racional diferente da ECT. Para Barzel as transações, por mais simples que sejam, podem ser decompostas em diferentes dimensões. Assim, se uma empresa adquire soja, na verdade transaciona um conjunto de dimensões: determinado nível de proteína, de umidade, presença ou ausência de grãos transgênicos, prazo da entrega, determinada tecnologia de produção orgânica, ou ainda pode desejar um produto cuja tecnologia de produção seja ambientalmente e socialmente compatível.

Cada dimensão de uma transação representa uma troca de direitos de propriedade e pode ser caracterizada por um custo de mensuração, e traz determinado valor para os partícipes da transação. Tal valor pode ser dissipado se os direitos de propriedade não forem devidamente definidos, o que pode ocorrer se for difícil medir (e, portanto, contratar) determinado atributo. Por exemplo, ser ou não um produto livre de GMO's é uma dimensão que pode ser facilmente medida, tal como o seu grau de umidade, o que permite a definição de contratos não ambíguos garantidos pelo Estado. Segundo Barzel, se puder ser medido a baixo custo, poderá ser contratado externamente à firma e ter o seu desempenho garantido pela justiça, no caso de quebra contratual.

Por outro lado, se as características da tecnologia de produção forem de mensuração mais custosa, sugere a necessidade de mecanismos especializados de monitoramento ou mecanismos sociais geradores de confiança. Desta forma Barzel sugere que as dimensões com custos de mensuração baixos, podem ser "contratadas" fora da firma, ou seja, podem ser transacionadas no mercado. São amparadas pela lei, uma vez que no caso de distorções, o adquirente pode acionar o provedor, que deve dar garantias para o produto. Já no caso de dimensões cujo custo 
de mensuração sejam mais difíceis, estas deverão contar com outros mecanismos de garantia que não têm a característica de um contrato. Ou seja, as partes se organizam privadamente para diminuir os riscos de perda de eficiência na transação, seja pelo desenvolvimento de mecanismos com base em reputação dos agentes, seja com base em laços sociais, seja realizando a transação internamente à firma.

Na sua essência a TCM associa os arranjos institucionais ao controle da perda de eficiência da transação devida à dificuldade de medir determinado atributo transacionado. A firma é vista como um conjunto de garantias ofertadas por um agente especializado, capaz de ofertar salvaguardas, gerando direitos sobre o resíduo (Barzel, 2002). As aplicações empíricas são menos desenvolvidas do que a ECT, entretanto a teoria é relevante ao estudo do surgimento de padrões, desenvolvimento de mercados de certificação e do surgimento de padrões de qualidade.

A Tabela 4 compara as duas vertentes teóricas nos seus aspectos essenciais, com destaque para o foco comum nos custos de transação e na busca da eficiência.

Tabela 4. Comparação entre a Economia dos Custos de Transação (ECT) e Teoria dos Custos de Mensuração (TCM)

\begin{tabular}{llll}
\hline Firma & Objetivo & Estrutura & Eficiência \\
\hline ECT & $\begin{array}{l}\text { Estrutura de } \\
\text { Governança }\end{array}$ & $\begin{array}{l}\text { Minimizar } \\
\text { Custos de } \\
\text { Transação }\end{array}$ & $\begin{array}{l}\text { Mercado (M) } \\
\text { Hierarquia (H) } \\
\text { Misto (X) }\end{array}$ \\
TCM & $\begin{array}{l}\text { Oferece Garantia } \\
\text { Para a Variabilidade } \\
\text { do Atributo }\end{array}$ & $\begin{array}{l}\text { Maximizar } \\
\text { Valor da }\end{array}$ & $\begin{array}{l}\text { Contrato } \\
\text { Transação }\end{array}$ \\
& & & \\
\hline
\end{tabular}

Fonte: O Autor.

A ECT teve relevante impacto empírico, com ênfase nos estudos de coordenação agro-industriais. A TCM tem menor impacto empírico, o que representa relevante possibilidade a ser explorada. Com base na economia dos contratos, a literatura de relações agro-industriais evoluiu significativamente desde o início dos anos 70. A seguir apontarei algumas das suas principais tendências. 


\subsection{Da Firma às Formas Híbridas: Evolução dos Estudos de Coordenação Agroindustrial}

Menos do que uma revisão da literatura ou uma cobertura de todas as vertentes possíveis, o presente tópico apresentará uma análise da evolução das abordagens conceituais recentes, com base no conceito de coordenação contratual da produção agrícola. Considerarei as relações entre agricultura e a indústria de insumos, a coordenação com a indústria processadora e sistemas de distribuição, bem como a coordenação horizontal. Tratarei de cinco abordagens, não necessariamente seqüenciais.

Abordagem dos Contratos: A primeira focaliza os contratos como elemento analítico, sem enfatizar a coordenação vertical. Nesta vertente podemos associar estudos sobre contratos de crédito, aluguel de terra, máquinas, e trabalho. Estudos clássicos são os de Cheung (1969) e Allen e Lueck (2002), o primeiro desenvolve uma teoria para o estudo dos contratos de terra, focalizando risco e custos transacionais. O segundo, influenciado pelo primeiro, expande o foco incluindo contratos de insumos e de produção. O livro de Allen e Lueck incorpora a dimensão da coordenação vertical e da organização da firma agrícola. No Brasil estudos de contratos na citricultura como os desenvolvidos por Azevedo (1996) e os estudos de franquias são representativos das análises de contratos de suprimento e distribuição.

Certamente o estudo de contratos específicos representa vertente crescentemente explorada, ancorada no estudo comparativo da eficiência de arranjos institucionais alternativos. A sua aplicação pode lançar luz sobre mecanismos alternativos de condução da atividade produtiva e representa uma linha analítica a ser explorada pelos economistas aplicados, sendo a transação individual a unidade analítica, capturada pelo contrato que lhe dá suporte.

Abordagem de Sistemas Agroindustriais: A inserção da agricultura na dimensão da coordenação vertical de produção foi tratada por diferentes autores e com motivações diferentes. Amparados pela teoria de organização industrial, nos EUA foram realizados estudos de coordenação nos anos 70 por Campbell e Hayenga (1978), Henderson e Schwart,Jr (1977) e Hayenga (1978), de certa forma predecessores dos subseqüentes estudos sobre coordenação vertical. Foi Ray Goldberg, na Universidade de Harvard, 
quem tratou o sistema agroindustrial de modo sistematizado, originando o termo “agribusiness”, para designá-lo. Davis e Goldberg (1957) sugerem que a agricultura há muito havia rompido com o isolamento setorial, e que suas relações com outros setores deveriam merecer estudo. Goldberg (1968) avançou nesta vertente consolidando o conceito de sistemas de agribusiness. A literatura surgida desta vertente é relevante, ancorada na teoria da organização industrial, entretanto não gerou estudos empíricos que pudessem explicar as formas alternativas de coordenação observadas nos inúmeros estudos de caso produzidos em Harvard nos anos 70, 80, 90, até o presente momento. Faltava uma teoria explicativa para os arranjos institucionais observados, entretanto a descrição dos sistemas agroindustriais da laranja, soja e trigo nos Estados Unidos são exemplos bem sucedidos de estudos gerados por Goldberg indicativos das vantagens de se romper com o foco exclusivo da produção rural, inserindo a necessidade de explorar a vertente do sistema produtivo.

Sob a ótica da Organização Industrial, vários estudos foram realizados no Brasil com o foco ampliado para as cadeias produtivas com destaque para Farina $(1997,1998)$, Marques (op. cit) entre outros.

Outros autores desenvolveram estudos de sistemas produtivos, com ênfase para a escola Francesa, como Morvan (1985) e outros. A origem da abordagem tem raiz na preocupação distributiva entre os agentes da cadeia agroindustrial. Os estudos conduzidos por Batalha (1993) exemplificam enfoque que focaliza aspectos afeitos à gestão da produção, na ótica das cadeias produtivas. Outra vertente que busca metrificar as relações entre segmentos dos SAG's é identificada nos estudos de quantificação de sistemas de Neves et al. (2004).

A abordagem dos sistemas mostrou ser relevante como uma primeira aproximação, mas não se preocupava com a possibilidade de testes empíricos e nem propunha uma teoria mais abrangente de coordenação vertical. A análise predominante era inter-setorial, não focalizando as firmas ou as formas alternativas de organização da produção.

Abordagem de Custos de Transação e Instituições: Partindo da contribuição de Goldberg, e lançando mão do uso da EC T de Williamson, surgiram estudos nos anos 80 que adicionaram embasamento teórico à abordagem de Harvard. Tal enfoque surgiu simultaneamente em diferentes países influenciados pelo surgimento da International 
Agribusiness Management Association, da International Society for the New Institutional Economics e, de modo particular, pela iniciativa da Universidade de Wageningen de sistematizar o estudo aplicado dos sistemas agroindustriais. Em estudos que exemplificam tal preocupação, Zylbersztajn (1995) e Saes e Farina (1999) apresentam uma proposta de utilização da teoria para o estudo da coordenação vertical, que adota instrumental da ECT e da análise macro-institucional aplicadas ao estudo dos sistemas produtivos descritivos de Harvard.

A abordagem reconhece a ruptura do isolamento da agricultura, sugerindo que análises desconectadas do sistema produtivo são parciais e não representariam a realidade. O uso associado das teorias de ECT e Organização Industrial mostrava ser compatível e útil para explicar os arranjos institucionais observados. Tanto os aspectos de economia dos custos de transação como elementos distributivos mereciam atenção ${ }^{18}$.

Em adição, a abordagem incluiu o papel das instituições que pautam o funcionamento dos sistemas agroindustriais. Ou seja, tanto os aspectos micro-organizacionais quanto os aspectos macro-institucionais, com ênfase na definição e garantia dos direitos de propriedade, são relevantes na abordagem de sistemas agroindustriais (SAGs), representado na Figura 3.

Figura 3. Modelo de SAG - Sistema Agroindustrial

Ambiente Institucional: aparato legal, tradições, costumes

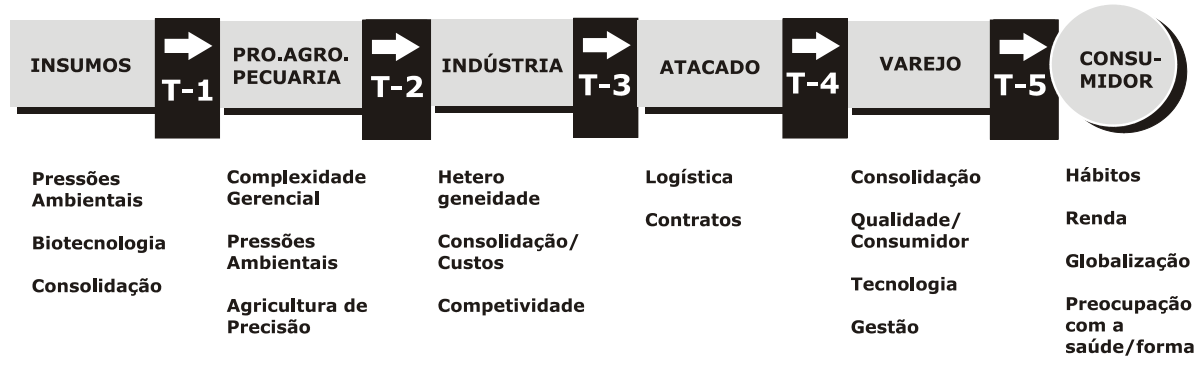

Ambiente Organizacional: organizações públicas e privadas, pesquisa, financeiras, cooperativas

Fonte: O Autor

${ }^{18}$ Na dinâmica do grupo de pesquisa do PENSA, percebíamos a perfeita composição entre ECT e a OI, mas não tínhamos elementos teóricos que nos dessem amparo. Até que surgiu o artigo de Joskow (1995) no Journal of Institutional and Theoretical Economics, que propunha exatamente esta abordagem. 
A estrutura analítica que passou a se denominar metodologia PENSA de estudos de sistemas agro-industriais nada mais é do que a composição de quatro etapas: na primeira, a descrição do sistema, à moda de Harvard, incluindo a análise da organização industrial de cada segmento que compõe o sistema. Na segunda etapa, o estudo das transações típicas entre segmentos do sistema, caracterizando os arranjos institucionais típicos observados nos SAG's. A ótica é da eficiência, associando a minimização dos custos de transação. Na terceira etapa a análise institucional é inserida no modelo, trazendo as regras que pautam o comportamento das organizações e sua influência sobre os agentes.

A abordagem teve foco agregado, em um primeiro momento, tendo utilidade para a definição de políticas públicas relacionadas aos SAGs. A análise setorial, típica da Organização Industrial, abria espaço e se compunha com a análise de coordenação inter-setorial. ${ }^{19}$

Diversos estudos mesclavam elementos descritivos dos SAG's com testes empíricos envolvendo a escolha de formas alternativas de organização. Pendiam diversas questões, em especial ligadas à simultaneidade das transações. Na ECT cada transação é estudada individualmente, entretanto no mundo real dos SAG's tínhamos clareza da simultaneidade das decisões estratégicas. O avanço da própria ECT e sua aplicação em sistemas complexos abriu as portas para as respostas.

\subsection{O Estudo das Formas Híbridas}

A conclusão de que o estudo das transações isoladas não permitia adequada análise da realidade, já é apontada por Williamson. A preocupação nos levou a observar que o mundo real é pontilhado por arranjos institucionais complexos, que envolvem um misto de transações realizadas via mercado, em conjunto com transações internas de forma verticalmente integrada e, de modo particular, o universo de contratos com desenho e formatos diversos, com múltiplos participantes e amparados por complexos mecanismos de salvaguardas.

Tal observação contribuiu para o avanço da economia das organiza-

\footnotetext{
${ }^{20}$ Esta literatura se distingue da literatura de indústrias organizados na forma de redes (network industries), tal como observada em telefonia, telecomunicações, entre outras.
} 
ções em geral, e na sua aplicação às relações entre agricultura e demais setores, em particular. Como demonstrarei, foi motivado pela análise empírica envolvendo formas complexas na agricultura Européia que a teoria encontrou motivação para se desenvolver.

Sub-Sistemas Estritamente Coordenados (SSEC): A redução do nível de agregação da abordagem de SAG, para um conjunto de transações estrategicamente conectadas, portanto em plano micro-organizacional, foi proposta por Zylbersztajn e Farina (1999). O conceito de sub-sistemas coordenados reconhecia a natureza contratual dos SAG's, reconhecia a relevância das instituições que limitam as ações dos agentes que atuam nos SAG's, e adicionalmente reconhecia que os contratos se dão entre agentes relacionados estrategicamente. $\mathrm{O}$ conceito permite o estudo de estratégias compartilhadas entre firmas individuais e tem sua utilização no estudo de estratégias que exijam a cooperação de distintos agentes ao longo do SAG agregado. Exemplos como a criação de padrões de qualidade, diferenciação de produtos entre outros, podem ser estudados sob a ótica proposta.

Figura 4. Sub Sistema Coordenado

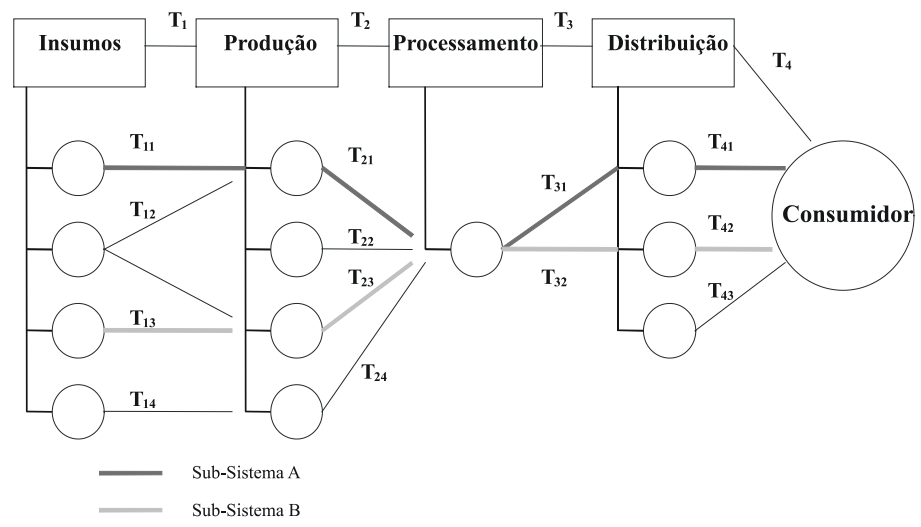

Fonte: Zylbersztajn e Farina (1997)

Em um SAG, podem ser encontrados diferentes sub-sistemas estritamente coordenados, que são arranjos organizacionais complexos, que envolvem simultaneamente muitos agentes. Se a análise do SAG utiliza um descritor da transação "típica" entre agentes "típicos”, no SSEC o foco 
são arranjos institucionais reais, quase sempre complexos e que diferem entre si nos seus detalhes. A observação de que existe variabilidade nos arranjos observados, soa como música aos ouvidos do pesquisador, pois permite estudar as razões e incentivos para a formação de diferentes arranjos. Hipóteses sugeridas pelas teorias podem ser testadas.

O uso dos conceitos de cadeias, de sistemas produtivos e de sub-sistemas coordenados, gerou um volume considerável de pesquisa empírica no Brasil e no exterior nas décadas de 1980, 1990 e na presente década. Os estudos são predominantemente descritivos, alguns quantificam e testam hipóteses associadas à eficiência comparativa de arranjos institucionais. Reardon (2005) cita o conceito de SSEC na sua análise da evolução da pesquisa em economia agrícola nos últimos 50 anos.

Arranjos Institucionais na Forma de Redes: A predominância de estudos de coordenação vertical reflete o desenho da teoria, de modo particular da ECT, cujo paradigma está centrado na temática da coordenação vertical da produção. Por outro lado a observação demonstra serem importantes os mecanismos horizontais de coordenação. Um olhar mais detalhado nos arranjos complexos observados mostra que existem complexos mecanismos de coordenação vertical em associação à coordenação horizontal, tratados na literatura de redes estratégicas ${ }^{20}$. $\mathrm{O}$ trabalho de Lazarinni,Chaddad e Cook (2000) reflete tal vertente e mostra como formas complexas podem ser descritas sob a ótica da coordenação dos agentes produtivos. O conceito de net-chain foi bem recebido na literatura internacional, representando relevante contribuição dos autores. O seu potencial empírico é relevante, merecendo aprimoramento conceitual-analítico.

Os autores propõem que a cooperação pode ocorrer tanto em níveis horizontais, como entre arranjos horizontais coordenados. As bases da cooperação podem variar desde a forma de transações via mercado, quanto com a inclusão de redes sociais e relações de confiança em formas contratuais complexas.

Estudos envolvendo formas de coordenação horizontal associadas à coordenação vertical envolvendo agricultura são desenvolvidos por Sauvèe (1998), e Zylbersztajn e Farina (2004), este último explora a potencialidade de externalidades de rede para explicar o surgimento de arranjos complexos. Tais estudos exploram os incentivos para a coopera- 
Figura 5. Resumo de Análise de Cadeia - Rede
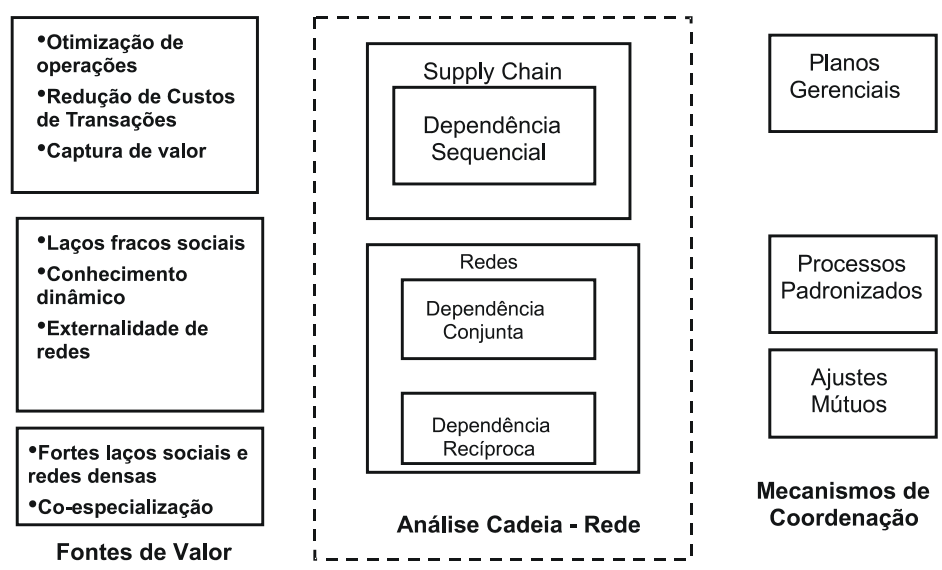

Mecanismos de Coordenação

Fonte: Lazzarini, Chaddad, Cook (2001)

ção horizontal em etapa anterior à da coordenação vertical. Aplicam-se a estudos de associações de produtores agrícolas (cooperativas ou não), que realizam investimentos específicos para produzir determinado atributo de qualidade, e na etapa seguinte podem exercer a escolha contratual de integrar-se verticalmente ou contratar com um agente especializado. A aproximação com o conceito de rede estratégica se dá pela existência de coordenação simultânea horizontal e vertical, bem como pela aplicação de mecanismos complexos de coordenação contratual que podem considerar mecanismos de exclusão, contratos complexos inter-temporais, decisões de integração vertical com múltiplos agentes, entre outros.

Arranjos Cooperativos: A coordenação horizontal, em especial nas organizações cooperativas encontrou relevante contribuição da Universidade de Missouri-Columbia, com a atuação de Michael Cook e colaboradores. O grupo que emergiu do programa de pesquisa liderado por Cook, vem produzindo regularmente uma contribuição nesta área com base em elementos da economia das organizações. Do mesmo modo se destacam Hendrikse na Holanda e Bialoskorski no Brasil Cabe destacar que o estudo comparativo da eficiência da organização cooperativa é um campo ainda a ser aprofundado na literatura internacional e no Brasil em particular. Em quais circunstâncias a organização cooperativa é mais eficiente do que a firma com fins lucrativos? A Economia das Organizações 
oferece relevante potencial a ser explorado na resposta a esta pergunta, incluindo as novas formas de alocação de direitos de propriedade, como observadas na denominada nova geração de cooperativas.

Formas Híbridas: Finalmente cabe destacar a fronteira da Economia das Organizações, o avanço conceitual e empírico das chamadas organizações complexas. A literatura inicialmente chamada de "formas estranhas", que segundo Coase, nada apresentam de estranhas, sendo exatamente as formas que os agentes produtivos encontram para implementar e coordenar a produção, dada a existência de custos de transação.

A contribuição recente do grupo ATOM, ligado à Sorbonne em Paris é relevante. Menard (2004) ${ }^{21}$ define as formas híbridas de organização que incluem clusters, redes, cadeias de suprimento, distribuição e contratos não padronizados. O autor apresenta o racional da ECT como base teórica e exemplifica com estudos empíricos desenvolvidos na área de alimentos e agricultura. O autor cita (p.160): "Two subsets have been more extensively studied. One is the supply-chain system adopted in many industries, with the typical example of the agri-fod sector". Dentro da ótica da ECT o autor desdobra a figura inicialmente desenvolvida por Williamson para explicar as decisões de formas alternativas de governança (mercado-contratos-hierarquia) (Figura 7). Como se utilizasse uma lente de aumento, Menard desdobra a fronteira de eficiência dos contratos, buscando destacar o papel das relações de confiança, redes relacionais, liderança e governança formalizada.

Destaco que as contribuições de autores como Menard, Valeseschini, Arrunada, Sauvée, Zuurbier, refletem a participação estruturada de diversas Universidades, em esforço para estudar a coordenação dos Sistemas Agro-Industriais europeus, após a incidência do mal da vaca-louca. O esforço envolveu a Sorbonne, Pompeu Fabra, Wageningen, entre outras Universidades, e indica como ações coordenadas podem trazer contribuições relevantes. O enfoque teórico utilizado no esforço conjunto foi baseado nas teorias aqui descritas, indicando a sua relevância para o estudo das formas modernas de coordenação agro-industrial.

Os aportes teóricos para os estudos dos sistemas agro-industriais

${ }^{21}$ Menard,C. 2004. The Economics of Hybrid Organizations. Journal of Institutional and Theoretical Economics, 160, 345-376. 
Figura 6. Escolha da Governança em Rede

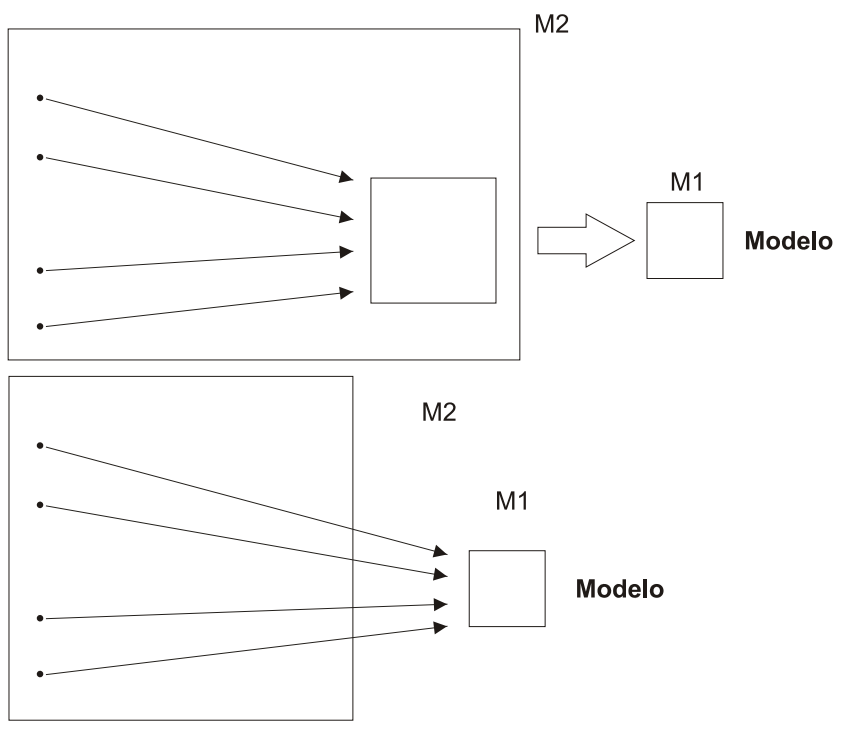

Fonte: Zylbersztajn, Farina (2004)

complexos são inúmeros. O que os distingue é a sua competência para explicar os fenômenos organizacionais que chamamos de "firmas", a sua existência e formas alternativas de organização. A predominância de alguma das vertentes será fruto do esforço de aplicação empírica, que representa o último teste comparativo da aplicabilidade das teorias. A evolução da teoria da firma, saindo do paradigma Walrasiano, tem sido muito relevante e os estudos empíricos aplicados à agricultura e produção de alimentos, nos oferece enorme campo para aplicação.

\section{Conclusões}

Diferentemente da observação de Allen e Lueck (2002, p.33) de que: “... In agriculture, however, contracts are often surprinsingly simple oral agreements lasting only one year.", entendo que os contratos que envolvem a atividade agrícola não são menos complexos do que aqueles observados em outras atividades produtivas. A sua complexidade e variabilidade representam um desafio e uma oportunidade para os estudiosos da Economia Agrícola em particular e da Economia Aplicada em geral. 
O estudo da variabilidade dos arranjos institucionais é um dos focos da Economia das Organizações aplicada ao estudo das relações entre o agricultor, seus fornecedores, seus canais de distribuição e suas parcerias, um campo amplo de estudos à espera de pesquisadores interessados.

Os grupos de pesquisa que se dedicam aos temas de coordenação contratual da agricultura crescem em todo o mundo. A criação do Contracting and Orgnizations Research Institute (CORI), na Universidade de Missouri-Columbia, indica o referencial que se estabelece. Economistas agrícolas, cientistas sociais, juristas, psicólogos se organizaram e deram novo formato ao programas de pós-graduação e de pesquisa em Economia Agrícola. Na Europa, além dos grupos já mencionados cabe destacar o grupo de Copenhagen da Royal Agricultural and Veterinary University com o trabalho de Kostas Karantininis, refletido nos encontros sobre Economia dos Contratos na Agricultura realizados a cada dois anos, e do livro de Bogetoft e Olesen (2004) sobre contratos na agricultura.

Figura 7. Tipologia das Organizações Híbridas

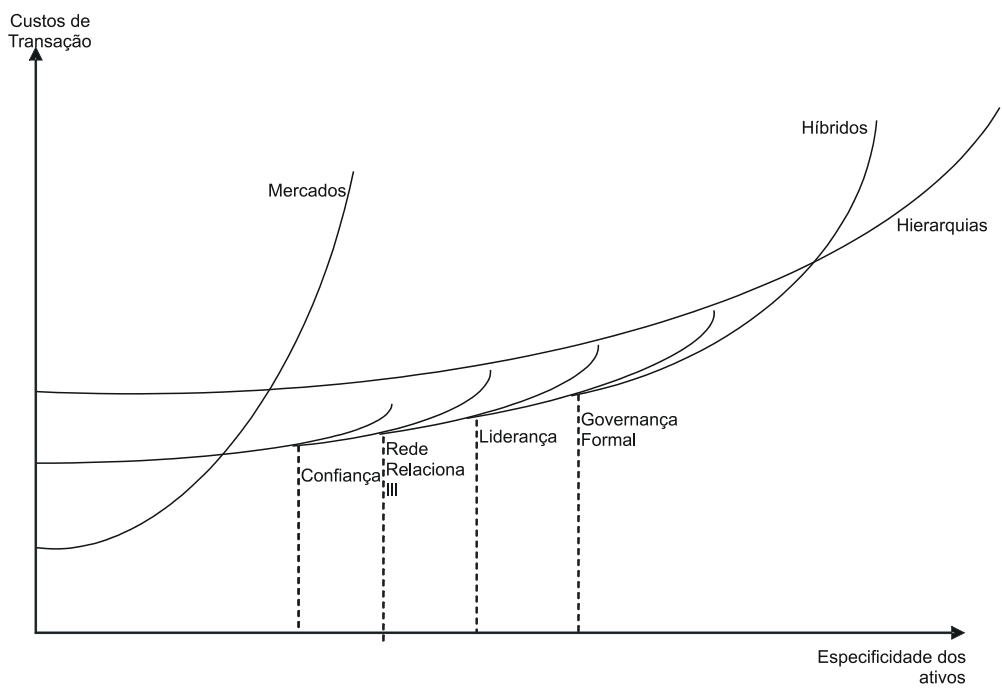

Fonte: Menard (2004)

A crescente presença de estudos sobre governança e formas contratuais na agricultura é observada nas sociedades internacionais como 
American Agricultural Economics Association, sua similar na Europa, e na International Society for the New Institutional Economics. Novos journals especializados surgiram como o "Supply Chain Management" na Inglaterra e "Journal of Chain and Network Science" na Holanda, ambos com relevantes contribuições na área agrícola.

No Brasil o tema foi incorporado aos principais programas de pesquisa abrindo a possibilidade de relevante agenda de pesquisa em Economia Aplicada. Alguns aspectos merecem comentários:

1. A abordagem de governança é micro-analítica e sugere o estudo das relações reais da produção. Apenas preços e quantidades não são suficientes para a condução analítica.

2. As estatísticas disponíveis, quando existem, enfatizam preços e quantidades e não os detalhes dos contratos e suas dimensões quantificáveis. Assim sendo, os pesquisadores precisam buscar seus próprios dados primários. A organização de bancos de dados de contratos tais como existem no CORI e, ainda incipientemente, no PENSA e CEDEO 22 , representa esforço necessário para o avanço empírico. É tempo para que os sistemas tradicionais de coleta de dados em Economia Agrícola, repensem suas estruturas de coleta de dados para que lancem um olhar sobre os contratos.

3. As metodologias utilizadas na pesquisa de ECT são as mesmas que são utilizadas na pesquisa econômica clássica. Métodos quantitativos são aplicáveis, necessários e muito relevantes, com atesta Sykuta (2005). Estudos de caso geralmente representam um bom enfoque para a primeira aproximação com a realidade, mas em geral não bastam, convidando o pesquisador a maior aprofundamento. Como qualquer outra metodologia, a de estudos de caso pode ser bem ou mal utilizada. Parte dos artigos recentes utiliza uma mescla de estudo de caso seguido por teste quantitativo.

4. A teoria econômica neoclássica é um referencial necessário sem o qual não se compreende a análise de governança. Qualquer disciplina de Economia das Organizações não prescinde de embasamento na teoria da firma tradicional bem como de formação em Organização Industrial. Evitá-la representa um erro. Por outro

${ }^{22}$ CEDEO - Centro de Estudos de Direito, Economia e Organizações. 
lado, existe uma família de teorias da firma de natureza contratual, cujo desenvolvimento dependerá da realização de estudos empíricos comparativos. Entendo ser uma grande oportunidade para os jovens pesquisadores em Economia Agrícola.

Agenda de Pesquisa: A agricultura, com sua abundância de formas complexas, nos oferece farto material empírico à espera de análise. Qualquer fenômeno que possa ser descrito na forma contratual é passível de estudo. Isto vai da economia de alianças estratégicas ao estudo da economia informal e à coordenação de sistemas agroindustriais internacionais, passando pelo surgimento de padrões e de mecanismos de garantia de qualidade. Destaco algumas vertentes, que considero particularmente importantes:

Coordenação de SAG's: Cresce em importância em resposta a desafios de segurança do alimento, certificações de diferentes naturezas, surgimento de padrões públicos e privados, mecanismos de solução de disputas (privados e públicos), problemas de descumprimento contratual, sistemas agroindustriais internacionais, inserção da variável ambiental na ótica dos sistemas agroindustriais, inserção da variável de responsabilidade social, estudos de quantificação de SAG's, competitividade internacional de SAG's, arranjos contratuais complexos, ambiente de negócios agroindustriais, entre outros.

Aspectos macro-institucionais: Representa uma linha de pesquisa centrada nas regras institucionais, sua gênese, mudanças e impactos nos arranjos institucionais. Associa-se ao estudo de economia política e de evolução institucional.

Estudos de Formas Híbridas: Focaliza a fronteira na área de contratos simultâneos, envolvendo tanto relações verticais quanto horizontais. Nesta vertente, tanto o estudo de contratos específicos, sua evolução ao longo do tempo e problemas pós-contratuais podem ser abraçados. Pode também focalizar contratos simultâneos na forma de redes. O desafio da formulação de testes empíricos é latente.

Uma agenda de pesquisa não pode ser dissociada de uma agenda de ensino. Em tal aspecto os cursos de Economia Aplicada podem criar disciplinas adicionais de Economia das Organizações, o que trará o aluno mais próximo do mundo das organizações reais. Os livros texto de Microecono- 
mia. como de Kreps (2003), e mais particularmente de Estratégia, como Besanko, Dranove e Shanley (2000) e, ou de Economia das Organizações como de Ricketts (2002), Hendrikse (2003), e o clássico de Milgrom e Roberts (1992) são livros fundamentais que trazem a teoria econômica ao mundo das organizações reais, sem perder o foco na qualidade da teoria.

Na pós-graduação a associação entre disciplinas de teoria microeconômica tradicional, economia das organizações e organização industrial confere excelente base para a condução de pesquisa. É inevitável considerar a rica interface que emerge entre as Ciências Jurídicas, Ciências Cognitivas e Economia, útil para as aplicações da teoria econômica.

Quanto ao esforço para publicar os resultados da pesquisa na área da Economia das Organizações, eu me alinho com as impressões do Professor Coase, durante reunião ocorrida no primeiro congresso ISNIE (Washington University em Saint Lowis, 1998), em reação à típica proposta de se criar mais um journal especializado: "Temos que produzir pesquisa de boa qualidade e publicar nas revistas existentes. A Nova Economia Institucional é apenas Economia”.

Finalizo retomando a questão motivadora apresentada na introdução. Por quê os economistas agrícolas relutam em adotar a perspectiva contratual da firma? Talvez a falta de dados sobre contratos, talvez a hegemonia do enfoque neoclássico, talvez o conservadorismo acadêmico. É necessário reconhecer que as teorias ainda são toscas, imperfeitas, pouco formalizadas quando comparadas à elegância da teoria neoclássica. São, por conseqüência, merecedoras de aperfeiçoamentos abrindo uma razão adicional para o nosso interesse. Não sei se tenho uma resposta a dar para o uso ainda limitado do enfoque contratual da firma, apenas lamento a perda de uma oportunidade para o avanço dos nossos programas em Economia Aplicada. Em meio a tantas mudanças e evolução teórica, apenas uma certeza: O Leiloeiro Walraziano agoniza.

\section{Referências Bibliográficas}

Allen,D.W. e Lueck,D.2002. The Nature of the Farm: Contracts, Risk, and Organization in Agriculture. MIT Press,258 p.

Azevedo,P.F.1996. Integração Vertical e Barganha. São Paulo: USP. Tese de Doutorado da Faculdade de Economia, Administração e Contabilidade. 
Barzel,Y.2002. Organization Firms and Measurement Costs. Congresso da International Society for the New Institutional Economics. Berkeley, California.

Batalha,M.O. (1993) La filière comme outil dánalyse strategique: le cas des matiers grasses a tartiner au Bresil. The se presentié a l’Institut National Polytechnique de Lorraine pour l'obtention du grade de Docteur de l'ÍNPL.

Besanko,D., Dranove,D and Shanley,M.2000. Economics of Strategy. John Wiley \& Sons,Inc. New York.644 p.

Binswanger, H. 1974. The measurement of technical biases with many factors of production. American Economic Review. 64(6):964-976.

Bogetoft,P. e Olesen,H.B. 2004. Design of Production Contracts: Lessons from theory and agriculture. Copenhagen Business School Press, 207 p.

Campbell,G.R. e Hayenga,M.L. (1978). Vertical Organization and Coordination in Selected Commodity Subsectors. Symposium at the American Agricultural Economics Association, Blacksburg, Virginia-USA.

Cheung,S.N.S. 1969. The Theory of Share Tenancy. The University of Chicago Press, 169 p.

Coase,R.H. 1937. The Nature of the Firm. 4 Economica N.S. 386-405.

Coase,R.H.1960. The Problem of Social Cost. 3, Journal of Law and Economics.1-44.

Davis,J.H. e Goldberg,R.A.1957. A Concept of Agribusiness. Division of Research. Graduate School of Business Administration. Harvard University, $136 \mathrm{p}$.

Demsetz,H. 1995. The Economics of the Business Firm: Seven critical commentaries. Cambridge University Press,179p.

Farina,E.M.M.Q., Azevedo,P.F. e Saes,M.S.M.1997. Competitividade: Mercado, Estado e Organizações. Editora Singular, 286 p.

Farina,E.M.M.Q e Zylbersztajn,D. 1998. Competitividade no Agribusiness Brasileiro. Relatório de pesquisa. IPEA. 
Goldberg,R.A.,1968. Agribusiness Coordination: A Systems Approach to the Wheat, Soybean, and Florida Orange Economies. Division Research. Graduate School of Business and Administration. Harvard University, 256 p.

Hart,O.1995. Firms, Contracts and Financial Structure. Clarendon Press, Oxford, 228p.

Hayenga,M.L. 1978. Vertical Coordination in the Beef Industry: Packer, Retailer and HRI Linkages. North Central Regional Research Project 117. University of Wisconsin-Madison.

Heady,E.O. and Dillon,J.L.1961. Agricultural Production Functions. Ames. Iowa State University, 667.p.

Henderson,D.R. e Schwart Jr,R.1977. Vertical Coordination Between Beef Cow/Calf Enterprises and Feedlots in the United States. NC 117 Beef Task Force. Unpublished paper.

Hendrikse,G.2003. Economics and Management of Organizations: coordination, motivation and strategy. McGRaw-Hill, UK.507 p.

Joskow,P.L.1995. The New Institutional Economics: Alternative Approaches. Journal of Institutional and Theoretical Economics, 151/1: 248-259.

Klein,B., Crowford,R.A, and Alchian,A.A.1978. Vertical Integration, Appropriable quasi-Rents and the Competitive Contracting Process. Journal of Law and Economics 21 (October):297-326.

Kreps,D. 2003. Microeconomics for Managers. 700 p. Norton.

Langlois,R.D.1998. Capabilities and the Theory of the Firm, in Foss and Loasby, Economic Organization, Capabilities and Co-ordination. Routledge Studies in Business Organization and Networks,300 p.

Lazzarini,S.G.,Chaddad,F.R.,Cook,M.L. 2001. Integrating Supply Chain and Network Analysis: The Study of Netchains. Journal of Chain and Network Science. Vol 1, n. 1, p 13-22.

MacDonald,J et al.2004. Contracts, Markets, and Prices: Organizing the Production and Use of Agricultural Commodities. USDA Economic Research Service. Agricultural Economic Report, \# 837. 
Martinez,S.W. and Zering,K. 2004. Pork Quality and the Role of Market Organization. USDA Economic Research Service. Agricultural Economic Report, \# 835.

Milgrom,P and Roberts,J.1992. Economics, Orgnization and Management. Prentice-Hall International, Inc. 621 p.

Neves,M.F.1995. Sistema Agroindustrial Citrícola: Um Exemplo de Quase Integração no Agribusiness. Dissertação de Mestrado. FEA-USP.

Neves,M.F, Zuurbier.P, Campomar.M.C. 2001. A model for the distribution channels planning process. Journal of Business \& Industrial Marketing. Vol 16, n. 7. pp.518-539.

Neves,M.F. 2004. A Framework for Mapping and Quantifying Value Chain Towards Collective Actions. European Marketing Academy Conference. Murcia, Spain.

North,D.C.1990. Institutions, Institutional Change and Economic Performance Cambridge University Press.152 p.

North,D.C.2005. Understanding the Process of Economic Change. Princenton University Press, $187 \mathrm{p}$.

Olson,M.1965. the Logic of Collective Action: Public Goods and the Theory of Groups. Harvard University Press.186 p.

Paes Leme, M.F. 2004. Determinantes da Escolha de Arranjos Institucionais: Evidências na Comercialização de Fertilizantes para Soja nos Estados de Goiás e Mato Grosso. Tese de Doutoramento apresentada ao Departamento de Administração da FEA-USP.

Pastore, A.C.1969. A Resposta da Produção Agrícola aos Preços no Brasil. Tese de Doutoramento. FEA - Universidade de São Paulo.

Pratt,J.W. and Zeckhauser,R.J.1985. Principals and Agents: The Structure of Business. Harvard Business School Press.241 p.

Reardon,T and C.P.Timmer.2005. Transformation of Markets for Agricultural Outputs in Developing Countries since 1950: How has thinking changed? In R.E. Evenson, P. Pingali, and T.P.Schultz. 2005. (editors) Vol 3 Handbook of Agricultural Economics: Agricultural \}Development: Farmers, Farm Prodction and Farm Markets. Elsevier Press. (no prelo). 
Ricketts,M.2002. The Economics of Business Enterprise: An introduction to Economic Organisation and the Theory of the Firm.Edward Elgar, UK, 590 p.

Thorelli, H.B.1986. Networks: Between Markets and Hierarchies. Strategic Management Journal.7, pp: 37-51.

Santos Silva,V.L. 2004. Ambiente Institucional e Organização de Redes de Franquias: Uma comparação entre Brasil e França. Tese de Doutoramento apresentada no Departamento de Engenharia da Produção da Universidade Federal de São Carlos.

Sykuta,M.E. 2005. New Institutional Econoetrics: The Case of Contracting in Organizations Research. Forthcoming in Glachant e Broussea. New Institutional Economics: A Textbook, Cambridge University Press.

Williamson,O.E. 1985. The Economic Institutions of Capitalism. The Free Press.449 p.

Williamson,O.E.1996. The Mechanisms of Governance. Oxford University Press, New york,Oxford.429 p.

Zylbersztajn,D.1996. Governance Structures and Agribusiness Coordination: A Transaction Cost Economics Based Approach. In Goldberg, R. Research in Domestic and International Agribusiness Management. Harvard University. JAI Press,310 p.

Zylbersztajn,D e Farina,E.M.M.Q. 1999. Strictly coordinated food systems: exploring the limits of the Coasian firm. International Food and Agribusiness Management Review 2, 249-65.

Zylbersztajn,D e Nogueira,A.C. 2002. Estabilidade e Difusão de Arranjos Verticais de Produção: uma contribuição teórica. Economia e Sociedade, vol 11, n.2.

Zylbersztajn,D e Nadalini 2004. Tomatoes and Courts. Artigo apresentado na reunião anual da SOBER

Zylbersztajn,D e Farina,E.M.M.Q.2004. Dynamics of Network Governance: A Contribution to the Study of Complex Forms. Paper presented at the Conference of Chains nd Networks at the University of Wageningen, The Netherlands. 
Zylbersztajn,D and Lazzarini,S.G. 2005 On the survival of contracts: assessing the stability of technology licensing agreements in the Brazilian seed industry. Journal of Economics and Business Organization, vol 5, pp103:120.

Zylbersztajn,D. 2005. Measurement Cost and Transaction Cost Perspectives of the Firm: two views about the same subject. Paper accepted to be presented at the Conference of the International Society for the New Institutional Economics, Barcelona, Spain.

Zylbersztajn,D, Florêncio, L.,Leles,C., Nogueira,A.C.L., Faccioli,F.2005. Towards the Improvement of the Business Environment in Brazilian Agriculture. Preliminary report. Tinker Foundation. University of São Paulo.

Recebido em julho de 2005 e revisto em agosto de 2005 